\title{
PERCEPTION OF SUCCESS AMONG PEOPLE PRACTISING MARTIAL ARTS AND COMBAT SPORTS
}

\author{
Wojciech J. Cynarski, ${ }^{1, A, B, D, E}$ Przemyslaw Pawelec, 2, C, D Jong-Hoon Yu, 3, B, E \\ Michal Vit, ${ }^{4,8}$ Jan Słopecki, ${ }^{5,8}$ Grzegorz Bielec, ${ }^{1, B}$ Krzysztof Kubala', ${ }^{1}$ \\ ${ }^{1}$ Department of Physical Education, University of Rzeszów, Rzeszow, Poland \\ ${ }^{2}$ International Martial Arts and Combat Sports Scientific Society, Rzeszow, Poland \\ ${ }^{3}$ Department of Health \& Human Performance, Glenville State College, Glenville, United States of America \\ ${ }^{4}$ Faculty of Sport Studies, Masaryk University, Brno, Czech Republic \\ ${ }^{5}$ European Jujutsu \& Kobudo Committee, Warsaw, Poland \\ A Study Design; ${ }^{\mathrm{B}}$ Data Collection; ${ }^{\mathrm{C}}$ Statistical Analysis; ${ }^{\mathrm{D}}$ Manuscript Preparation; ${ }^{\mathrm{E}}$ Funds Collection \\ Address for corpespondence: \\ Przemyslaw Pawelec \\ International Martial Arts and Combat Sports Scientific Society \\ Towarnickiego 3, 35-959 Rzeszów, Poland \\ E-mail: przemyslaw.pawelec@idokan.pl
}

\begin{abstract}
Ahstract A scientific framework for this study is the Humanistic Theory of Martial Arts, and the psychology of sport using the concepts of goal, task and success.

The problem and aim of this study was an explanation of "perception of success" in groups of adults practising martial arts. Is perception of success influenced by the respondents' social background or the type of martial art practised? Would there be any differences in results depending on their country of origin and residence, and if so, what results?

The research was done within the framework of the IMACSSS.1A/2011: "Social determinants of participation in martial arts schools and clubs". The tool was Perception of Success Questionnaire, which was used to survey a number of respondents from the United States, the Czech Republic and Poland, who were selected randomly and participated voluntarily. The statements and calculations have been ranked by more or less contact forms of martial arts.

The results obtained in this study indicate a poor relationship between perception of success and the type of fighting style practised and a measurable relationship between the perception of success and social origin. There is a weak relationship in perception of success by respondents from American or European cultures.
\end{abstract}

Key WOrls ego orientation, task orientation, martial arts, combat sports, Perceptions of Success in Sport Questionnaire

\section{Introduction}

The first part of the scientific framework for this study concerns the holistic Anthropology of Martial Arts and the Humanistic Theory of Martial Arts (Cynarski, 2012; Zeng, Cynarski, Xie, 2013). In this perspective, we analyse the Martial Arts and Combat Sports (MA\&CS) holistically, with physical and technical components, and also values 
and motivations of people practising it. It is important what type of MA\&CS is practised, and who is the teacher and the student (Obodynski, Cynarski, 2005; Vertonghen, Theeboom, 2012; Cynarski, 2013).

The second part of the background is the psychology of education (Elliot, 2006), and its application for the psychology and sociology of sport, using concepts of goal, task and success; e.g. by Nicholls (1984) and his achievement goal theory. There are two types of goal orientation: learning orientation and performance orientation. Both are parts or manifestations of the motivational processes affecting learning.

Perception of success and task orientation are important issues in the psychology of sport and modern coaching, pedagogy and physical education, as well (Nicholls, 1984; Ames, 1992). Goal orientation is an important part of a personal motivational profile in sport (Moreno Murcia, Cervelló Gimeno, Cutre Coll, 2007; Holgado Tello, Navas Martínez, López Núñez, García Calvo, 2010).

Some authors focus on the philosophy of martial arts for explanation of their impact onto perception of success and aspirations (Back, Kim, 1979; Kim, Back, 2000; Cynarski, 2013; Cynarski, Lee-Barron, 2014). Sociocultural conditions of the martial arts perception and internalization of the special ethos are indicated quite often (Dykhuizen, 2000; Cynarski, Sieber, Litwiniuk, 2005; Obodynski, Cynarski, 2005; Zeng, Xie, Cynarski, 2013).

Social stratification refers to a multi-level system of layers. It is measured by the availability of five basic social resources: power, money, prestige, knowledge, education and health. The "layer" refers to the community "separate due to the similar lifestyles, customs, income levels and awareness of the barriers separating it from others, especially the lower communities" (Szczepanski, 1970).

We assume here the stratification proposed by William L. Warner, who in his research, in order to assess the stratification, has adopted the following criteria: education, occupation, wealth, titles, membership in clubs, and neighbourhood of residence. He took into account indicators including economic and social prestige, and stated that through the layers he understood two or more groups of people who believed themselves to be occupying in society higher or lower positions. He distinguished three layers (higher, middle and lower), which were divided into sub-layers. Hence, the model was created in the shape of a pyramid with the following characteristics of layers: 1) A1 - higher higher - old families that inherited their wealth from their fathers and grandfathers (on the top of the pyramid); 2) A2 - higher lower - new families, factory owners, businesspeople who made a fortune by themselves (nouveau riche); 3) B1 - average higher - doctors, lawyers, professors, directors and managers of companies; 4) B2 - average lower - small traders, artisans, clerks, highly-qualified workers, people with their own houses in the suburbs; 5) $\mathrm{C1}$ - lower higher - semi- and unskilled workers with a permanent job, the residents of tenement houses, people with incomes spent entirely on current expenditure; 6) C2 - lower lower - people with bad reputation, slum dwellers, the homeless, beggars (Szczepanski, 1970). For this study it was assumed that people practising martial arts, sports and combat systems belong to the layers C1, B2, B1, A2.

Another differentiating factor was the attitude of the respondents to the two types of objectives: "physical health, mental well-being, improvement of the fitness level and independence - achieving personal challenges and acquiring a definite position - which all resemble task orientation. In turn, the motives of participation in sports activity resemble ego orientation" (Beck, Monastyrska, Wojciechowska, Szrajda, 2013).

The problem and aim of this study was the explanation of "perception of success" in groups of children and young people practising combat sports and martial arts. Based on this, it was examined how the use of these forms of physical activity and belonging to different social groups and gender influence the beliefs of these people regarding 
the possibility of success not only in sports and martial arts. The added value of this study is its internationalization, as the groups of practicioners belong to different culture.

Two research problems were posed. The first problem of the research was an attempt to determine the importance of the social dimension of perception of success in groups of adults practising martial arts, comparatively, in Poland, the Czech Republic and the USA. The questions posed by the research included: Is there a relationship between the perception of success by the respondents, and their social background? The second research problem concerned the determination of the possible emergence of differences in the perception of success in groups of adults martial arts practitioners (and comparatively, in Poland, the Czech Republic and the USA). Therefore, the research question was: Are there any differences in the results according to the country of origin and residence and what they might signify?

In connection with the above issues and research questions the following hypotheses were adopted: 1) There is no statistically significant relationship between the perception of success in martial arts and social origin; 2) Differences in the statements of the respondents from different countries are mainly due to cultural differences.

\section{Material and Method}

The research was done within the framework of the IMACSSS.1A/2011: "Social determinants of participation in schools and clubs of martial arts". It is a Project, under auspices of the Division of Sociology and Anthropology and the Division of Pedagogy the International Martial Arts and Combat Sports Scientific Society (IMACSSS). This project involved research, in which various methods and techniques were used. The study was approved by the Ethical Committee of Idokan Poland Association (Scientific society which cooperates with IMACSSS).

The Perception of Success Questionnaire (POSQ) was used in this study. The authors of this tool (Glyn C. Roberts, Darren C. Treasure, Gloria Balague) identified two indicators with reference to motivation - "task" ( $T$ ) and "ego" (E) orientations. The task orientation ( $T$ ) defines success as achieving mastery - concentration on improving one's own skills, striving for perfection, overcoming difficulties and reaching a goal; thus, the demonstration of ability is self-referenced and success is realised when mastery is demonstrated. The ego-involving goal orientation (E), in turn, defines it as outperforming others, rivalry orientation, comparing with opponents and a positive assessment of own actions. The ego goal orientation, then, is the predisposition to evaluate success in terms of demonstrating a better ability than others, especially if little effort is expended (Roberts, Treasure, Balague, 1998). This tool (standardized psychological test) contains a scale of answers to choose from.

The study was conducted between October 2015 to January 2016 in the United States (New York), the Czech Republic (Brno) and in Poland (Rzeszów, Skarżysko-Kamienna, Strzyżów, Warsaw). The number of respondents, randomly selected, and with their voluntary participation was $N=182$ (respectively 32, 34 and 116) people. The percentage of men and women by country is presented in Table 1.

Table 1. Demographic characteristics of respondents based on gender

\begin{tabular}{lrrrrrrrr}
\hline \multirow{2}{*}{ Gender } & \multicolumn{2}{c}{ USA } & \multicolumn{2}{c}{ Czech Republic } & \multicolumn{2}{c}{ Poland } & \multicolumn{2}{c}{ Summary } \\
\cline { 2 - 9 } & N & $\%$ & N & $\%$ & N & $\%$ & N & $\%$ \\
\hline Women & 7 & 3.85 & 6 & 3.32 & 27 & 14.80 & 40 & 21.90 \\
Men & 30 & 16.48 & 28 & 15.30 & 84 & 46.10 & 142 & 78.10 \\
\hline
\end{tabular}


Due to a significant difference in the number of respondents between the Czech Republic (34 persons), the United States (32 persons) and Poland (116 persons) an overwhelming dominance of Poles (46.17\%) was observed in comparison to the number of men from the Czech Republic (15.38\%), Polish women (14,8\%) and American men (16.48\%). In contrast, a small minority were the Czech men (3.32\%) and American women (3.85\%).

The data on age diversity found among survey respondents is shown in Table 2.

Table 2. The mean of age of respondents

\begin{tabular}{lcccc}
\hline \multirow{2}{*}{ Gender } & USA & Czech Republic & Poland & Summary \\
& $\bar{x}$ & $\bar{x}$ & $\bar{x}$ & $\bar{x}$ \\
\hline Women & 20.34 & 28.30 & 22.90 & 23.64 \\
Men & 25.38 & 27.10 & 23.34 & 25.16 \\
\hline
\end{tabular}

The mean of age of the respondents (men and women) from three countries was varied. The highest mean was recorded in the case of people practising martial arts in the Czech Republic (women 28.3 years, men 27.1 years). Then there were the Americans (25.38 years), Poles (23.3 years) and Polish women (22.29 years). On average, the youngest people among the respondents were from the United States (20.34 years).

This questionnaire contained twelve affirmative sentences (in the form of answers) and the scale of their potential acceptance or rejection. These sentences expressed the following attitudes: 1) "I beat other people"; 2) "I am clearly superior"; 3) "I am the best"; 4) "I work hard"; 5) "I show clear personal improvement"; 6) "I outperform my opponents"; 7) "I reach a goal"; 8) "I overcome difficulties"; 9) "I reach personal goals"; 10) "I win"; 11) "I show other people I am the best"; and 12) "I perform to the best of my ability" (Roberts et al., 1998).

The subjects rated their relationship to the above sentences based on the scale from A (Strongly agree) through $C$ (Neutral) to $E$ (Strongly disagree). Individual responses were assigned a corresponding rank (1-5). It should be noted that the questions 4, 5, 7-9 and 12 were classified as Task orientation, and 1-3, 6, 10 and 11 - Ego orientation (Roberts et al., 1998). The results were used in the analysis measuring the acceptance of these attitudes and possibly occurring correlations. It is assumed that the Poles and the Czechs would be portrayed as persons from the European cultural area, and residents of the United States - the American.

\section{Results}

The first hypothesis presupposed a lack of statistically significant dependence between the perception of success in the martial art practised and social origin. Both Task orientation and Ego orientation were taken into account. In addition, in order to examine thoroughly the problem of the presence or absence of a statistically significant relationship, the statements and calculations have been ranked by more or less contact forms of martial arts (arithmetic mean, standard deviation, coefficient of variation and the strength of relationships between variables based on Spearman correlation). The level of significance is $p<0.05$. The results obtained (using Statistica software and LibreOffice Calc) are shown in Table 3.

They assumed that martial arts, combat sports and combat systems were divided according to their contact intensity. The category "Combat sports and combat systems" included MMA, kickboxing, judo, taekwondo, and 
Krav Maga. "Martial arts (non-contact)" included modern jujitsu, goshin-ryu jujitsu, jujitsu styleless, idokan jujitsu, karate idokan, karate isshin-ryu, iaido, goshinjutsu, jujitsu, chow gar, aikibudo, kung fu, and aikido.

Table 3. The perception of success and the kind of cultivated martial arts

\begin{tabular}{lcccccc}
\hline \multirow{2}{*}{ Orientation } & \multicolumn{3}{c}{ Combat sports and combat systems } & \multicolumn{3}{c}{ Martial arts (non-contact) } \\
\cline { 2 - 7 } & $\bar{x}$ & SD & $V(\%)$ & $\bar{x}$ & SD & $V(\%)$ \\
\hline Task & 1.81 & 0.82 & 45.3 & 1.72 & 0.83 & 48.25 \\
Ego & 2.55 & 1.03 & 40.4 & 2.92 & 1.14 & 39.05 \\
\hline
\end{tabular}

The data contained in Table 3 indicate a variation in the responses of people practising sports, combat systems and martial arts in the subject line success (in the form of purpose and self-development).

Coefficient of variation (given in percentage), "ego orientation", and "task orientation" is between 20 and $40 \%$ (39.05\%) and between 40 and $60 \%(40.4 ; 45.3 ; 48.25)$, so the diversity of statistical data can be placed between the mid and high range.

The results of Spearman correlation was 0.36 . This means that there is a weak correlation between the type of practised fighting styles and perception of success.

Verification of the first hypothesis takes into account the perception of success by the respondents characterised by social origin. The results are shown in Table 4.

Table 4. The perception of success and social origin

\begin{tabular}{|c|c|c|c|c|c|c|c|c|c|c|c|c|}
\hline \multirow{2}{*}{ Orientation } & \multicolumn{3}{|c|}{ Layer lower higher } & \multicolumn{3}{|c|}{ Layer average lower } & \multicolumn{3}{|c|}{ Layer average higher } & \multicolumn{3}{|c|}{ Layer higher lower } \\
\hline & $\bar{x}$ & SD & V & $\bar{x}$ & SD & V & $\bar{x}$ & SD & V & $\bar{x}$ & SD & V \\
\hline Task & 2.73 & 1.34 & 49.10 & 2,12 & 0.92 & 43.40 & 1.92 & 0.94 & 48.90 & 2.12 & 0.89 & 41.99 \\
\hline Ego & 2.41 & 1.13 & 46.80 & 2.31 & 1.01 & 43.70 & 2.51 & 1.15 & 45.80 & 3.30 & 1.47 & 44.55 \\
\hline
\end{tabular}

The data contained in Table 4 shows a variation in the response of representatives of sports and combat systems and martial arts belong to a distinguished social strata (which are of social origin) in the subject achieve the objective and self-development.

The values of the coefficient of variation (in percentages) "ego orientation" and "task orientation" are between 40 and 60 percent $(41.99 ; 43.4 ; 43.7 ; 44.55 ; 45.8 ; 46.8 ; 48.9 ; 49.1)$, so that there is a large variation in statistical data.

The Spearman's rank correlation coefficient between social origin and perception of success is $r_{s}=0.42$. This means that there is a moderate correlation. Moreover, the significance of calculated ratio is 6.17 . Because this value is higher than 0.05 , it means that we must confirm the hypothesis concerning the lack of a statistically significant dependence between the perception of success in martial arts and social origin.

The second hypothesis was on the differences in the statements of the respondents from countries belonging to the American (United States) and European (Czech Republic and Poland) cultural area, and on the perception of success. Also in this case Task orientation and Ego orientation were taken into account as well as statements and calculations ranks related to cultural area. The results are shown in Table 5. 
Table 5. The perception of success and cultural area

\begin{tabular}{lcccccc}
\hline \multirow{2}{*}{ Orientation } & \multicolumn{3}{c}{ American } & \multicolumn{3}{c}{ European } \\
\cline { 2 - 7 } & $\bar{x}$ & SD & $V(\%)$ & $\bar{x}$ & SD & $V(\%)$ \\
\hline Task & 2.02 & 1.04 & 51.48 & 2.04 & 1.02 & 50.00 \\
Ego & 2.34 & 1.12 & 47.87 & 2.21 & 1.22 & 55.20 \\
\hline
\end{tabular}

Coefficient of variation (given in percentage) "ego orientation" and "task orientation" is between 40 and $60 \%$ $(47.87 ; 50 ; 51.48 ; 55.2)$, so that there is a large variation in statistical data.

The result of Spearman's rank correlation coefficient is $r_{s}=0.39$, which means that there is a weak relationship between the representation of the American or European cultural area and the perception of success. Moreover, the significance of calculated ratio is 5.77 . Because this value is higher than 0.05 , it means that we must accept the hypothesis concerning a lack of a statistically significant dependence between the perception of success in martial arts and the origin of the cultural area.

The result of the analysis of the perception of success is also interesting because of the gender of the respondents. The obtained data is presented in the Table 6.

Table 6. The perception of success according to men and women

\begin{tabular}{lcccccc}
\hline \multirow{2}{*}{ Orientation } & \multicolumn{3}{c}{ Women } & & \multicolumn{3}{c}{ Men } \\
\cline { 2 - 7 } & $\overline{\mathrm{x}}$ & $\mathrm{SD}$ & $\mathrm{V}(\%)$ & $\overline{\mathrm{x}}$ & $\mathrm{SD}$ & $\mathrm{V}(\%)$ \\
\hline Task & 1.77 & 0.66 & 37.29 & 1.85 & 0.93 & 50.27 \\
Ego & 1.91 & 0.82 & 42.93 & 2.20 & 1.08 & 49.10 \\
\hline
\end{tabular}

The data contained in Table 6 indicates a lack of diversity in the responses of women and men on the subject of achieving the objectives and self-development.

Coefficient of variation (given in percent) "ego orientation" and "task orientation" is between 20 and 40 percent (37.29) and between 40 and 60 percent $(42.93 ; 49.1 ; 50.27)$, so the diversity of statistical data can be placed between the mid and high range.

The result of Spearman's rank correlation coefficient is $r_{s}=0.34$. This means that there is a weak relationship between gender and perception of success.

\section{Discussion}

Respondents practising combat sports and combat systems agreed that success depended on achieving specific objectives, the outcome was similar to the response "other" than "definitely". While they were neutral towards the claims that it was equally important orientation for self-development (percentage of replies situated them between consent and neutrality). In the case of martial arts' practicioners these results were presented in analogy, the responses to "ego orientation" were closer towards "disagree." While the standard deviation in individual cases indicated a lack of diversity in the responses given. 
Social background of a person is determined by 1) personal level of education; 2) parental level of education; and 3) profession. It was assumed that these indicators are associated with membership to a particular social class, expressed inter alia by socio-professional categories (Gillbert, 2017). In this case, the social layer is divided into middle, higher and lower classes. However, due to the lack of responses concerning acquired and performed parental professions and the previously analysed level of practitioner's education, the survey was limited merely to the description of the parental level of education as a factor for determining the social background of the respondents.

Respondents representing a lower higher, average lower and higher lower neutral layer responded to the opinion that success depends on achieving the specific objectives, but "rather" coincides the claims of persons from an average higher layer.

In the case of "ego orientation" neutral posture was kept by the representatives of the lower higher layer, average lower and average higher, attitudes "disagree" - the higher lower layer. Besides, the standard deviation values indicated no significant differences in the responses given.

The data contained in Table 5 indicate a lack of diversity in the responses of representatives of sports and combat systems and martial arts belong to the appropriate social class. Respondents from the American cultural area expressed a neutral position towards the opinion that success depends on achieving specific objectives and that equally important is oriented self-development. In the case of persons belonging to the European cultural area, these results were similar. In contrast, the standard deviation indicated no significant differences in the answers provided.

The data contained in Table 6 indicate a lack of diversity in the responses of women and men on the subject of achieving the objectives and self-development. Women agreed that success depends on achieving specific objectives and that orientation for self-development is equally important. Men also agreed with the statement that success depends on achieving the goal, but expressed a neutral attitude towards the opinion that success is related to self-development. Standard deviations indicated no significant differences in the responses given.

This popular tool (POSQ) was used in some similar research connected with young people who practise and play sports (Escartí, Roberts, Cervelló, Guzmán, 1999; Beck et al., 2013; Gómez-López, Granero-Gallegos, Abraldes, Rodríguez-Suárez, 2013; Guelmami, Jbabli, Barhoumi, Hamrouni, Agrebi, 2014). According to Salinero Martín, Ruiz Tendero and Sánchez Bañuelos (2006), "Task orientation correlated with motivation-effort in order to achieve success, with sports practice enjoyment, anxiety over stressful situations and with a lower learning commitment and dedication." However, martial arts have their own specifics.

The results (shown above) are generally compatible with some similar research on what affects people practising martial arts (King, Williams, 1997; Boyd, Weinmann, Yin, 2002; Vertonghen, Theeboom, 2012; Zeng, Cynarski, 2016). However, authors' own research presented above brings new knowledge on the perception of success among martial artists. Poor dependence on the indications of that perception with varying social origin, gender and cultural area indicate that in the era of globalization a significant unification of cultural patterns takes place in Western countries. There were no significant differences between trainees of martial arts and combat sports in some earlier studies (Vertonghen, Theeboom, 2012; Witkowski, Cynarski, Blazejewski, 2013). In studies by Vertonghen, Theeboom and Pieter (2014) social diversity in relation to the cultivated varieties of martial arts and combat sports was observed, but a tool POSQ studied only young people aged between 11 and $18(\mathrm{~N}=33$ ). Quite often, the statement is a correlation between the level of aggressiveness and orientation on the target, and 
practising harder, more contact varieties of combat sports. Significantly, "more immigrants were found among kick-I Thai boxers" (Vertonghen et al., 2014; King, Williams, 1997; Vertonghen, Theeboom, 2012; Witkowski et al., 2013).

\section{Conclusions}

Undoubtedly, this issue requires further research and on a larger scale, in training environments, different varieties of martial arts, combat sports and related systems. The novelty of this study is multidimensionality (culture, kind of martial art or sport pracised, and aim/perception of success).

The results obtained in this study indicate a weak relationship between the perception of success and the kind of cultivated fighting styles, and moderate relationship between the perception of success and social origin. In addition, there is a weak relationship in the case of the perception of success and representation of the American or European cultural area.

Poor dependence on the indications of perception the success with the cultural area and gender may indicate that in the era of globalization there is a substantial unification of cultural patterns. However, the limited scope of the study and a small number of groups does not allow for unambiguous generalizations.

\section{References}

Ames, C. (1992). Classrooms: goals, structures, and student motivation. Journal of Educational Psychology, 3 (84), 261-271. DOI: 10.1037/0022-0663.84.3.261.

Back, A., Kim, D. (1979). Towards a Western philosophy of the Eastern martial arts. Journal of the Philosophy of Sport, 6, 19-28. DOI: 10.1080/00948705.1979.10654147.

Beck, O., Monastyrska, E., Wojciechowska, M., Szrajda, J. (2013). Achievement goals in exercise and sport from the public health perspective. Hygeia Public Health, 4 (48), 505-508.

Boyd, M., Weinmann, C., Yin, Z. (2002). The relationship of physical self-perceptions and goal orientations to intrinsic motivation for exercise. Journal of Sport Behavior, 1 (25), 1-18.

Cynarski, W.J. (2012). Martial Arts Phenomenon - Research and Multidisciplinary Interpretation. Rzeszow: Rzeszow University Press.

Cynarski, W.J. (2013). General reflections about the philosophy of martial arts. Ido Movement for Culture. Journal of Martial Arts Anthropology, 3 (13), 1-6. DOI: 10.14589/ido.13.3.1.

Cynarski, W.J., Lee-Barron, J. (2014). Philosophies of martial arts and their pedagogical consequences. Ido Movement for Culture. Journal of Martial Arts Anthropology, 1 (14), 11-19. DOI: 10.14589/ido.14.1.2.

Cynarski, W.J., Sieber, L., Litwiniuk, A. (2005). Perception, understanding and adaptation of Asian martial arts in the West: a sociological analysis. Archives of Budo, 1, 13-18.

Dykhuizen, J.C. (2000). Culture, training, and perception of the martial arts: Aikido example. Journal of Asian Martial Arts, 3 (9), 9-31.

Elliot, A. (2006), The Hierarchical Model of Approach-Avoidance Motivation. Motivation and Emotion, 2 (30), 111-116. DOI: 10.1007/ s11031-006-9028-7.

Escartí, A., Roberts, G.C., Cervelló, E.M., Guzmán, J.F. (1999). Adolescent goal orientations and the perception of criteria of success used by significant others. International Journal of Sport Psychology, 3 (30), 309-324.

Gillbert, D. (2017). The American Class Structure in an Age of Growing Inequality. SAGE Publication: Thousand Oaks.

Gómez-López, M., Granero-Gallegos, A., Abraldes, J.A., Rodríguez-Suárez, N. (2013). Analysis of Self-Determined Motivation in Basketball Players through Goal Orientations. Collegium Antropologicum, 3 (37), 707-715.

Guelmami, N., Jbabli, S., Barhoumi, M., Hamrouni, S., Agrebi, B. (2014). Cross cultural validity of the Arabic version of Perception of Success Questionnaire (Children's Version). Indian Journal of Applied Research, 1 (4), 468-471. DOI: 10.15373/2249555 X/ JAN2014/145.

Holgado Tello, F.P., Navas Martínez, L., López Núñez, M., García Calvo, T. (2010). A structural model of goal orientation in sports: personal and contextual variables. The Spanish Journal of Psychology, 1 (13), 257-266.

Kim, D., Back, A. (2000). The Way to Go: Philosophy in Martial Arts Practice. Seoul: Nanam. 
King, L.A., Williams, T.A. (1997). Goal orientation and performance in martial arts. Journal of Sport Behaviour, 4 (20), $397-411$.

Moreno Murcia, J.A., Cervelló Gimeno, E., Cutre Coll, D.G. (2007). Young athletes' motivational profiles. Journal of Sports Science and Medicine, 2 (6), 172-179.

Nicholls, J.G. (1984). Conceptions of ability and achievement motivation. In: R. Ames, C. Ames (eds.), Research on motivation in education (pp. 39-73). San Diego, CA: Academic Press.

Obodynski, K., Cynarski, W.J. (2005). Social and Philosophical Determinants of the Lifestyle of a Contemporary Student of Martial Arts. In: B. Hodan (ed.), Tělesná vychova, sport a rekreace v procesu současné globalizace (pp. 271-281). Olomouc: Univerzita Palackeho v Olomouci.

Roberts, G.C., Treasure, D.C., Balague, G. (1998). Achievement goals in sport: The development and validation of the Perception of Success Questionnaire. Journal of Sports Sciences, 4 (16), 337-347. DOI: 10.1080/02640419808559362.

Salinero Martín, J.J., Ruiz Tendero, G., Sánchez Bañuelos, F. (2006). Orientación y clima motivacional, motivación de logro, atribución de éxito y diversión en un deporte individual. Ciencias Aplicadas a la Actividad Física y el Deporte, 1, 5-11.

Szczepanski, J. (1970). Elementarne pojęcia socjologii. Warszawa: PWN.

Vertonghen, J., Theeboom, M. (2012). Martial arts and youth: an analysis of contextual factors. International Journal of Adolescence and Youth, 4 (17), 237-241. DOI: 10.1080/02673843.20 12.687689.

Vertonghen, J., Theeboom, M., Pieter, W. (2014). Mediating factors in martial arts and combat sports: An analysis of the type of martial art, characteristics, and social background of young participants. Perceptual \& Motor Skills: Exercise \& Sport, 1 (118), $41-61$. DOI: 10.2466/06.3 0.PMS.118k14w3.

Warner, W.L. (1949). Social Class in America. Chicago: Science Research Associates Incorporated.

Witkowski, K., Cynarski, W.J., Blazejewski, W. (2013). Motivations and determinants underlying the practice of martial arts and combat sports. Ido Movement for Culture. Journal of Martial Arts Anthropology, 1 (13), 17-26. DOI: 10.14589/ido.13.1.3.

Zeng, H.Z., Cynarski, W.J. (2016). Participation Motivations of Taekwondo Athletes/ Students. Saarbrücken: Lambert Academic Publishing.

Zeng, H.Z., Cynarski, W.J., Xie, L. (2013). Martial Arts Anthropology, Participants' Motivation and Behaviours. Martial Arts in Chanshu: Participants' Motivation, Practice Times and Health Behaviours. Saarbrücken: Lambert Academic Publishing.

Zeng, H.Z., Xie, L., Cynarski, W.J. (2013). Young Martial Arts Athletes' Motivation and their Health-Related Behaviours. Research Quarterly for Exercise and Sport, 1 (84), A78-A79.

Cite this article aS: Cynarski, W.J., Pawelec, P., Yu, J.-H., Vit, M., Słopecki, J., Bielec, G., Kubala, K. (2018). Perception of Success among People Practising Martial Arts and Combat Sports. Central European Journal of Sport Sciences and Medicine, 1 (21), 67-75. DOI: 10.18276/cej.2018.1-08. 